Centro Universitário de Brasília - UniCEUB Faculdade de Ciências da Educação e Saúde - FACES Curso de Psicologia

AMAMENTAÇÃO: MITOS NO INÍCIO DA GRADUAÇÃO EM PSICOLOGIA

MADALENA BRAGA

Brasília

Setembro, 2020 
Centro Universitário de Brasília - UniCEUB Faculdade de Ciências da Educação e Saúde - FACES Curso de Psicologia

\section{AMAMENTAÇÃO: MITOS NO INÍCIO DA GRADUAÇÃO EM PSICOLOGIA}

\section{MADALENA BRAGA}

Pesquisa apresentada ao Centro Universitário de Brasília como requisito . Professor-Orientador: Marina Kohlsdorf

Brasília

Setembro, 2020 


\section{Sumário}

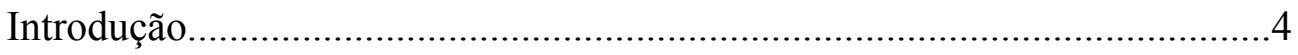

A amamentação....................................................4

Benefícios do aleitamento materno..................................5

Rede de apoio................................................ 7

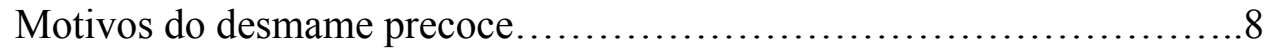

Mitos................................................................. 10

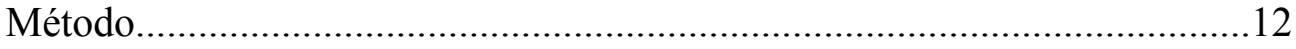

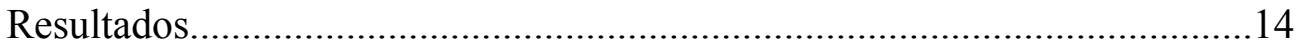

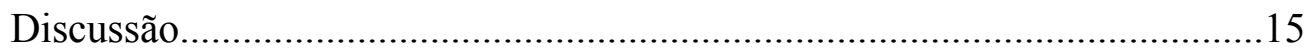

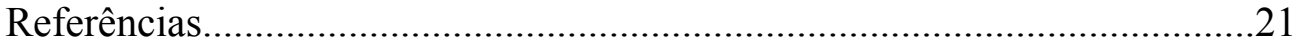




\section{Introdução}

A amamentação

A amamentação provém de um dos impulsos biológicos, instintivos e comportamentais mais importantes de todos os recém-nascidos de mamíferos, garantindo-lhes vida; no entanto o ato de outra pessoa levar a criança ao seio de forma voluntária, não sendo algo puramente instintivo, é de característica comportamental (Vaucher \& Durman, 2006).

Os primatas, incluindo chimpanzés e humanos, necessitam da lactação, a qual depende de reflexos e instintos do bebê, combinado com as ações maternas, sendo apoiado e guiado socialmente. Todos os mamíferos são dependentes da mãe, não sendo capazes de dar continuidade à própria vida de forma independente. A amamentação, segundo Vaucher \& Durman (2006), “garante ao recém-nascido alimentação adequada, proteção contra infecções e segurança por estar próximo a progenitora". Os recém-nascidos precisam dos cuidados de adultos por um longo período, exigindo principalmente proteção, nutrição e manutenção da temperatura.

$\mathrm{Na}$ antiguidade a nutrição era uma das únicas formas de proteger-se contra doenças, devido ao desconhecimento sobre fisiologia e patologias, então os seres humanos se utilizavam da alimentação para reagir às agressões externas e até mesmo como meio de proteção no contexto psicossocial e meio externo, por ser algo indispensável e essencial ao ser humano. A amamentação desde o nascimento é de grande importância para os bebês, pois em seu início está presente o colostro (imunidade passiva), o tipo de leite com mais componentes essenciais, e estimula a produção de ainda mais leite (Vaucher \& Durman, 2006).

Mesmo com tantos benefícios do aleitamento materno, deve-se considerar a escolha consciente e ponderada da mãe da criança pela não amamentação. Deve ser lembrado também 
que a mulher tem o direito, reconhecido pelo Estado, de amamentar, mesmo se ela possui um trabalho em tempo integral (Brasil, 2003).

\section{Benefícios do aleitamento materno}

A importância da amamentação é uma discussão bastante atual, somente em 1980 foram publicados pela primeira vez estudos que comprovaram a importância da exclusividade da amamentação, sem a adição de qualquer outro tipo de líquido, o que leva a um menor risco de morbidade e mortalidade. Inclusive esses estudos foram utilizados para formular as bases da Organização Mundial da Saúde (OMS) e do Fundo das Nações Unidas para a Infância (UNICEF), os quais recomendam a amamentação de forma exclusiva até os 6 meses, e que posteriormente, de forma gradativa começa-se a ingestão de outros alimentos, mas mantendo a amamentação até ao menos dois anos de idade (Toma, Rea, 2008).

O início da ingestão de outros alimentos a partir dos 6 meses é recomendada para que se possa suprir as novas necessidade nutricionais de uma criança em crescimento. No entanto é importante reforçar a necessidade de manter a amamentação que supre, segundo Toma e Rea (2008) “75\% das necessidades de energia, 50\% das de proteína e 95\% das de vitamina A, além da proteção imunológica”.

A grande importância do leite materno se constitui na grande complexidade biológica e riqueza em nutrientes, contendo carboidratos, proteínas, gorduras e vitaminas em quantidade ideal, o que representa a principal fonte de alimento para os recém-nascidos (Freitas et al, 2008).

Essa nutrição promove a redução de infecções no lactente, a gastroenterite e otites, alergias, síndromes metabólicas (Ferreira et al, 2010), diarreia e doenças respiratórias, 
permitindo o crescimento e desenvolvimento saudável da criança. A amamentação, segundo Marques, Cotta e Priore (2011), leva a redução de doenças crônicas, como as autoimunes, celíaca, de Crohn, colite ulcerativa, linfoma, diabetes mellitus e alergia alimentar, entre outras. E o ato de sucção exercidos durante o ato de amamentar fortalece os músculos da face e posteriormente leva ao desenvolvimento do processo da dentição e da fala. (freitas et al, 2008). Outro benefício da amamentação é o vínculo mãe e filho, o qual influencia no desenvolvimento psicológico da criança (Ferreira el al 2010; Freitas et al, 2008; Marques 2011).

Os benefícios do aleitamento materno alcançam também a mãe da criança, segundo diversos autores sabe-se que existe uma relação entre amamentar e apresentar menos doenças em relação a mães que não amamentam. As lactantes apresentam menos “doenças como o câncer de mama, certos cânceres ovarianos, e certas fraturas ósseas, especialmente coxofemoral, por osteoporose" segundo os estudos de Rea (2004).

Outros estudos apontam como benefícios a amenorréia pós parto, que é a ausência da menstruação, o que permite um distanciamento entre as gestações. A mulher que amamenta retorna ao peso pré-gestacional com mais facilidade e rapidez, é também reduzida a chance de sangramento uterino posterior ao parto, promovendo uma involução uterina provocada pela liberação da ocitocina, e evitando possíveis anemias (Rea, 2004; Marques, Cotta e Priore, 2011).

No que se refere à família, os benefícios da amamentação estão relacionadas com a praticidade, custo e estímulo à ligação mãe-bebê. Conforme Marques, Cotta e Priore (2011) é de grande relevância que em países em desenvolvimento haja uma orientação sobre a alimentação do lactente para que além de ser adequada à sua condição socioeconômica, venha 
a informar os benefícios da lactação, quando e como iniciar a alimentação complementar, quais alimentos adotar de acordo com os recursos disponíveis e as necessidades da criança.

Para o Estado, a grande vantagem do aleitamento materno é seu baixo custo, pois se for comparado a alimentação da criança com fórmulas infantis ou com outros tipos de leite de origem animal ou vegetal. A fórmula mais utilizada, o leite de vaca, é mais cara que uma alimentação complementar (após 6 meses), a qual consiste em frutas e legumes basicamente, somado ao leite materno que não possui custos (Marques, Cotta e Priore, 2011). A diminuição dos riscos de doença para o bebê e mãe também diminuem os gastos com saúde do estado, pois se promove a prevenção através da amamentação.

Rede de apoio

Todos os indivíduos possuem redes sociais, onde existe comunicação, interação, relações, auxílio... "é um conjunto de relações interpessoais que vinculam indivíduos a outros indivíduos" (Montes, Leal e Pontes, 2013). Os seres humanos sobrevivem através da interdependência entre si, atendendo à necessidades temporárias ou de longo tempo. Mas todos possuem uma rede social mais próxima onde existe apoio e confiança, é a rede de apoio. No contexto da amamentação deve-se existir uma rede de apoio eficiente, onde se promova o incentivo ou não da amamentação, a depender das condições presentes. Segundo Montes, Leal e Pontes (2013) “a cultura e as tradições podem prevalecer em relação às orientações dos profissionais de saúde”, pois sem isso haveria grandes dificuldades quanto à adesão do aleitamento. A amamentação, portanto, não é somente uma prática instintiva ou automática, é guiada pela subjetividade e experiência feminina, influenciada também pelo contexto social 
em que vivem. Com isso vê-se a importância do apoio ao redor da mãe e bebê para promover um ambiente saudável e propício à amamentação.

Motivos de desmame precoce

Apesar dos esforços dos profissionais da saúde e até da Organização Mundial da Saúde a informações sobre os benefício do aleitamento materno não alcançaram toda a sociedade, e muitas mães realizam o desmame precoce, que consiste na interrupção do aleitamento materno antes do 6 meses da criança, independente do motivo (de Abreu, Fabbro, \& Wernet, 2013).

O desmame precoce está presente no cenário brasileiro, e existem diversos motivos. Dentre eles, os que levam ao desmame precoce ressaltam os fatores sociais, biológicos, culturais e econômicos. Percebe-se que a amamentação se fundamenta na vivência e subjetividade da mulher, condicionando-se ao seu meio social. Com isso tem-se que as interações sociais devem ser consideradas e estudadas com maior detalhe na abordagem prática de amamentar ou não, pois não está somente no âmbito fisiológico de alimentar a criança, vai além (de Abreu, Fabbro, \& Wernet, 2013).

A questão da mulher no mercado de trabalho trouxe diversas mudanças na sociedade, e uma delas são os cuidados dos filho e a amamentação. Reconsiderar o desmame precoce entre as mulheres inseridas no mercado de trabalho, é, segundo REA (1997), "questionar pressuposições que sempre existiram", e apesar dos estudos da autora serem não tão novos, ainda se questiona muito o papel da mulher no lar (de Abreu, Fabbro, \& Wernet, 2013).

Um grave problema existente entre as mulheres trabalhadoras é a noção de que as leis trabalhistas de proteção à grávida e lactante, a garantia de emprego, licença-maternidade 
remunerada, creche e pausas para amamentar, leis preconizadas pela OIT ( Organização Internacional do Trabalho) desde o início do século, são condições eficientes para não haver o desmame precoce (de Abreu, Fabbro, \& Wernet, 2013).

No entanto verifica-se que não é o suficiente, pois as mulheres em sua maioria não levam seus bebês ao trabalho para se utilizarem das folgas para amamentar (podem morar distante de suas casas também), além de não existirem creches em todos os locais, dificultando a mãe de ter onde deixar a criança durante o período de trabalho. O estudo de Rea (1997) verificou que as mulheres em áreas metropolitanas não conseguem sair de seus trabalhos para irem amamentar nas pausas que possuem por direito, preferem utilizar essas horas para sair mais cedo.

Outro fator que interfere no desmame precoce é a faixa etária da mãe, num estudo de Freitas et al (2008) verificou-se que quanto menor a idade, menor o tempo de amamentação. Isso pode ser explicado por a gravidez em adolescentes poder vir acompanhada de vários riscos, entre eles a imaturidade física e psicológica e a maior probabilidade de complicações gestacionais e problemas médicos que interfiram no curso normal da gestação (Freitas et al, 2008).

Outros fatores que podem ser relacionados ao aleitamento materno e sua duração é a escolaridade. Pesquisas descrevem uma relação proporcional entre tempo de estudo e melhores cuidados maternos, incluindo tempo saudável de amamentação exclusivo, ou seja, quanto maior o tempo de estudo, maior o tempo de amamentação (Freitas et al, 2008).

A situação conjugal das lactantes também influenciam no tempo de amamentação; as mulheres casadas ou em relação estável com o companheiro passam mais tempo amamentando. Isso pois esse fato pode representar um apoio se houver colaboração positiva do companheiro para a prática da amamentação. A ausência do parceiro apoiador da mãe e a 
existência de famílias desestruturadas podem representar fatores para o insucesso do aleitamento materno, tanto por problemas financeiros, exigindo mais a presença da mãe no mercado de trabalho, quanto emocionais e sociais (Freitas et al, 2008).

Mitos

Um fator de grande importância de desmame precoce, se não o mais importante, são os mitos acerca da amamentação. Existem mitos sobre a amamentação que são passados de gerações em gerações ou criados com a ignorância que o desconhecimento científico provoca (Simões et al, 2015). Por mito entende-se "como a representação de fatos ou personagens reais, exagerada pela imaginação popular, pela tradição" (Marques, Cotta, Priori, 2011). Já a tradição é uma transmissão oral de lendas, fatos, etc., que perpassam gerações, idades e culturas. Com isso o mito é a própria tradição, sendo o oposto da verdade e está presente na vida social e cultural, podendo explicar fenômenos e explicações para diversos assuntos para a sociedade. O mito, quando acreditado, funciona como forte estímulo na condução de pensamentos e posteriormente de comportamentos dos seres humanos ao lidarem com as realidades existenciais (Marques, Cotta, Priori, 2011).

Os mitos perpassam não somente as pessoas em geral, mas também os profissionais da saúde, pois esses devem considerar a existência dos mitos e trabalhar através deles. Os profissionais da saúde tendem a considerar o ato de amamentar somente como algo natural, olhando o aspecto físico somente. Faz-se necessário a identificação dos mitos e crenças adquiridos culturalmente pela mãe e sua rede de apoio, sobre a lactação, para assim reconhecer quais as necessidades e fatores que interferem na manutenção da amamentação. $\mathrm{O}$ 
que permite uma ação mais eficaz na resolução dos problemas, podendo prolongar e favorecer a lactação (Marques, Cotta, Priori, 2011).

Alguns estudos discorrem sobre quais seriam esses mitos, estando entre eles falta de conhecimento da fisiologia da lactação, qualidade do leite produzido, tamanho da mama, recusa do bebê em pegar peito e a crença de que o leite industrializado (NAN) é igual ou melhor que o leite materno (Marques, Cotta, Priori, 2011; Simões et al, 2015).

Esses mitos existem em todos os âmbitos, entre leigos e profissionais da saúde; o universitário que acaba de ingressar na graduação provavelmente traz como bagagem o "senso comum", que é permeado por mitos. Essa pesquisa busca, como objetivo, verificar o conhecimento dos alunos de início de graduação da área da saúde, especificamente da Psicologia, acerca da amamentação, seus mitos e conhecimentos científicos. 


\section{Método}

\section{Participantes}

Colaboraram com a pesquisa estudantes de primeiro semestre do curso de Psicologia do UniCEUB, a qual durou em média 20 minutos por aplicação. Foram escolhidos alunos da Psicologia para se obter conhecimentos específicos de alunos dessa área sobre a amamentação. Os horários escolhidos de aplicação foram os disponíveis na faculdade, além de maior concentração de alunos por sala. Além disso alguns dados demográficos, tais como idade, sexo, escolaridade, estado civil, renda e religião, dos alunos foram coletados nesse mesmo período.

\section{Local}

A pesquisa ocorreu em salas de aula do Campus da Asa Norte do UniCEUB. As salas foram de tamanho médio (20 a 30 alunos por sala), por volta de 10 metros quadrados, com 40 carteiras, climatizada e razoavelmente silenciosa. A pesquisadora permaneceu em sala de aula durante a pesquisa.

\section{Materiais}

Foram utilizados os questionários de pesquisa, que continham 100 perguntas cada, que foi produzido em outra pesquisa acerca do mesmo tema, e disponibilizado pela orientadora, 
com a autorização da autora; impresso em papel A4 e o TCLE, os quais os participantes deveriam preencher com caneta e devolver à pesquisadora.

Procedimentos

O projeto foi apresentado ao comitê de ética para aprovação, e posteriormente se iniciou a aplicação da pesquisa. Fez-se contato com professores de primeiro semestre de Psicologia para autorização da utilização da sala de aula por eles utilizada.

A aplicação ocorreu em duas salas de aula no decorrer de uma semana. Apresentou-se aos alunos a proposta do questionário, e aqueles interessados em respondê-la o fizeram naquele mesmo momento. Foram entregues a cada participante o questionário de 100 questões (com respostas de verdadeiro, falso ou não sei) e o TCLE em duas vias; não havia tempo limite de aplicação, no entanto o tempo médio foi de 20 minutos.

Coleta de dados

Os participantes entregaram os questionários respondidos, e posteriormente foram analisados os dados. Foram obtidos o número de acertos de cada participante, questões mais acertadas e as mais erradas, comparações entre idade e acertos entre outros dados. 


\section{Resultados}

O questionário foi respondido por 50 pessoas, com idades entre 17 e 49 anos, com uma média de 21,9 anos. Foram abordados diversos mitos quanto à amamentação e também conhecimentos científicos (componentes do leite, benefícios, etc) para se verificar não somente crenças, mas também conhecimentos mais aprofundados acerca do tema.

6 pessoas $(12 \%)$ já possuíam outra graduação, e todos os participantes possuíam ensino médio completo, a renda não foi informada pela maioria (eram todos estudantes sem renda fixa), e dentre os participantes 43 (86\%) eram do sexo feminino e 7 (14\%) do sexo masculino. Dos participantes somente $5(10 \%)$ relataram já terem tido filhos e amamentado. A média geral de acertos foi de 38,74 de 5000 respostas, sendo que o pior índice foi de 1 acerto e o melhor de 72 acertos. As respostas discriminadas por sexo estão na tabela 1.

Tabela 1

Discriminação de respostas comparando-se o sexo

\begin{tabular}{llll}
\hline & Erros & Acertos & Não sabe \\
\hline Sexo feminino (43) & $16,5 \%$ & $40,9 \%$ & $42,6 \%$ \\
Sexo masculino (7) & $12,4 \%$ & $25,4 \%$ & $62,4 \%$ \\
\hline
\end{tabular}




\section{Discussão}

Esse estudo foi aplicado para alunos de primeiro semestre de cursos da saúde, por isso praticamente todos $(88 \%)$ apresentavam o mesmo nível de escolaridade, ensino médio completo, e $12 \%$ estavam na segunda graduação; e a minoria já havia amamentado (10\%).

O mito mais aparente e mais respondido como correto foi "É aconselhável fazer massagens nos seios logo antes de amamentar, para deixar o leite materno mais liquefeito e menos empedrado", outro mito foi "Amamentar dói o seio". Outros itens de conhecimentos quanto a amamentação com mais erros nas respostas foram "A amamentação reduz o risco de a mulher desenvolver síndrome metabólica (doenças cardíacas e diabetes) após a gravidez, inclusive para aquela que teve diabetes gestacional", "Amamentar protege a mãe do câncer de mama e ovário", os quais eram ditos como falsos ou "não sei" (tabela 2).

Essas questões demonstraram pouco conhecimento dos estudantes acerca de questões que envolvem a saúde da mulher e os benefícios da amamentação para a mãe.

Os itens com maior número de acertos estavam relacionados à questões sociais e psicológicas da criança e da mãe, tais como “A amamentação com leite materno contribui para a saúde emocional do bebê e da mãe", "Estresse, ansiedade e cansaço podem prejudicar a amamentação" e "O momento de amamentação aumenta o vínculo entre mãe e filho e colabora para que a criança se relacione melhor com outras pessoas".

Dois itens possuíram o maior número de acerto (92\% de participantes acertaram), foram “O leite materno é o alimento mais completo e equilibrado, pois atende todas as necessidades de nutrientes e sais minerais do bebê até os 6 meses de idade" e "Quem faz redução mamária ou colocou silicone não poderá amamentar", o primeiro item demonstra um conhecimento 
básico positivo da amostra quanto aos benefícios do leite materno para os lactentes. Já o segundo item corresponde à um conhecimento estético, que um procedimento de cirurgia plástica poderia ou não causar (a resposta correta do item é "falso", ou seja, as mulheres que realizam esses procedimentos podem sim amamentar).

\section{Tabela 2}

Itens com maiores e menores números de acertos

\begin{tabular}{|c|c|}
\hline Item & $\begin{array}{l}\text { Número de } \\
\text { acertos }\end{array}$ \\
\hline $\begin{array}{l}\text { O leite materno é o alimento mais completo e equilibrado, pois atende todas as } \\
\text { necessidades de nutrientes e sais minerais do bebê até os } 6 \text { meses de idade }\end{array}$ & 46 \\
\hline Quem faz redução mamária ou colocou silicone não poderá amamentar & 46 \\
\hline $\begin{array}{l}\text { Quando a mãe produz muito leite, a doação a bancos de leite pode prejudicar a } \\
\text { amamentação do filho }\end{array}$ & 39 \\
\hline Estresse, ansiedade e cansaço podem prejudicar a amamentação & 38 \\
\hline Mãe que trabalha fora não pode amamentar & 38 \\
\hline $\begin{array}{l}\text { O momento de amamentação aumenta o vínculo entre mãe e filho e colabora para } \\
\text { que a criança se relacione melhor com outras pessoas }\end{array}$ & 37 \\
\hline $\begin{array}{l}\text { A amamentação com leite materno contribui para a saúde emocional do bebê e da } \\
\text { mãe }\end{array}$ & 36 \\
\hline $\begin{array}{l}\text { É aconselhável fazer massagens nos seios logo antes de amamentar, para deixar o } \\
\text { leite materno mais liquefeito e menos empedrado }\end{array}$ & 1 \\
\hline $\begin{array}{l}\text { Amamentar durante uma segunda gestação pode prejudicar o desenvolvimento do } \\
\text { bebê no útero }\end{array}$ & 3 \\
\hline
\end{tabular}




\begin{tabular}{|l|l|}
\hline $\begin{array}{l}\text { A amamentação reduz o risco de a mulher desenvolver síndrome metabólica (doenças } \\
\text { cardíacas e diabetes) após a gravidez, inclusive para aquela que teve diabetes } \\
\text { gestacional }\end{array}$ & 4 \\
\hline Amamentar dói o seio & 5 \\
\hline Agua quente estimula a produção de leite & 5 \\
\hline Amamentar protege a mãe do câncer de mama e ovário & 6 \\
\hline Algumas mães produzem um leite mais fraco & 6 \\
\hline
\end{tabular}

Na tabela 3 pode-se observar que entre os 5 participantes com maior número de acertos 3 já haviam amamentado, demonstrando que a prática da amamentação auxilia em um maior conhecimento quanto ao assunto.

Tabela 3

5 Participantes com maior número de acertos, relacionados à idade, escolaridade, sexo e amamentação

\begin{tabular}{|c|l|l|l|l|}
\hline Número de acertos & Idade & Amamentou? & Escolaridade & Sexo \\
\hline $\mathbf{7 2}$ & 43 & Sim & Segunda Grad. & Feminino \\
$\mathbf{7 0}$ & 30 & Não & Segunda Grad. & Feminino \\
$\mathbf{6 6}$ & 20 & Sim & Primeira Grad. & Feminino \\
$\mathbf{6 2}$ & 22 & Sim & Primeira Grad. & Feminino \\
$\mathbf{6 2}$ & 20 & Não & Primeira Grad. & Feminino \\
\hline
\end{tabular}

Entre os 5 melhores resultados $100 \%$ eram do sexo feminino e a média de idade era de 27 anos, média maior que a média de idade geral (21,9 anos). Dentre as 6 pessoas que já possuem outra graduação, 2 estavam entre as com o maior número de acertos, no entanto isso 
pode somente indicar uma maior idade e maior chance de já haver amamentado; no entanto a figura 1 indica a proporção de acertos quanto a graduação, mostrando que as pessoas com maior grau de instrução possuem mais acertos.

Figura 1

Proporção de acertos por graduação

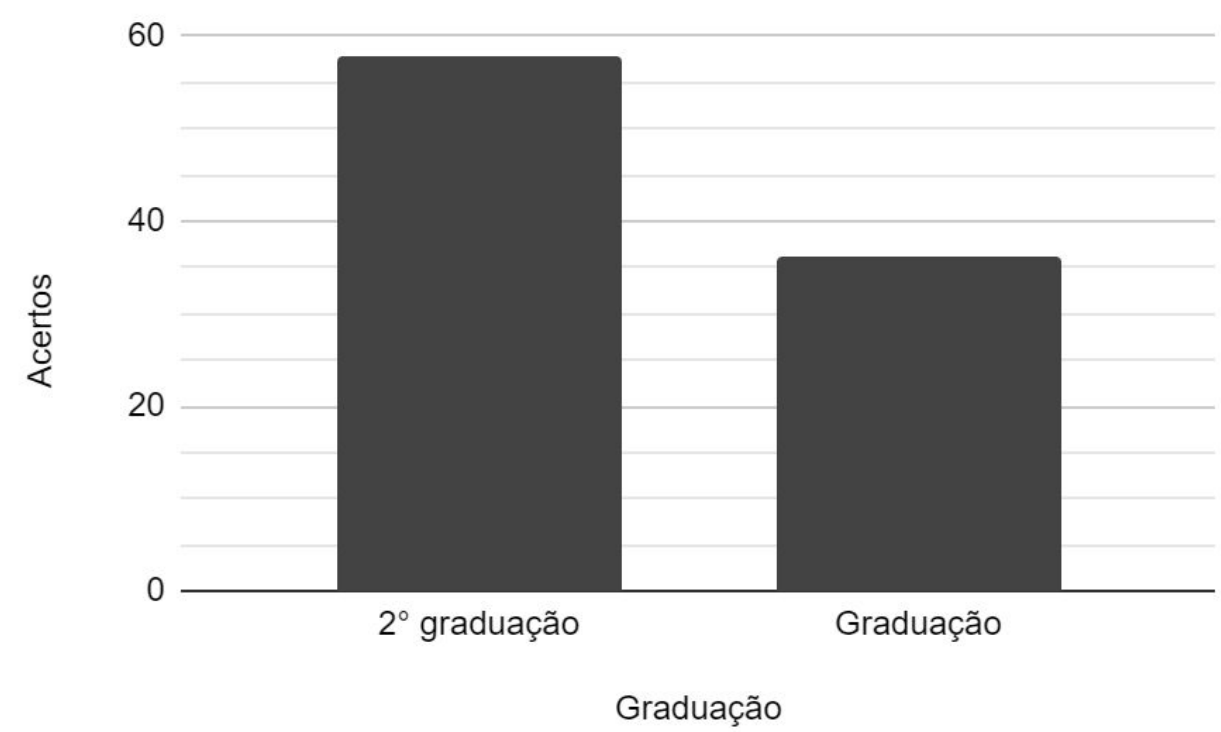

Figura 2.

Tendência de acertos conforme a idade

60

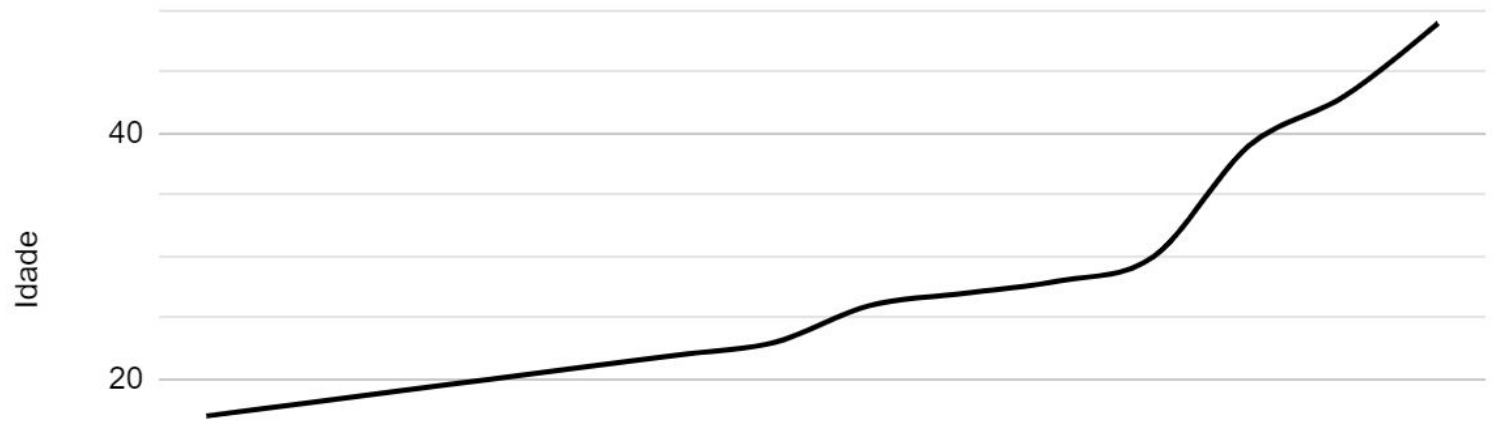

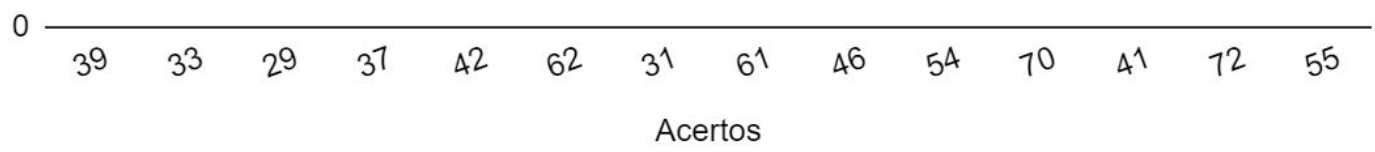


O maior grau de instrução está ligado à idade, pois pessoas com mais graduações provavelmente possuem mais idade, na figura 2 de figura a tendência de acertos conforme a idade e se corrobora a ideia de que quanto maior a idade e maior o grau de instrução menos mitos se carregam.

Na tabela 4 observa-se os 5 participantes com pior desempenho, os quais tinham uma média de idade de 19,8 anos, e média de 8,4 (16,8\%) de acertos no questionário.

Tabela 4

5 participantes com o menor número de acertos, relacionados à idade, escolaridade, sexo e amamentação

\begin{tabular}{|c|l|l|l|l|}
\hline Número de acertos & Idade & Amamentou? & Escolaridade & Sexo \\
$\mathbf{1}$ & 19 & Não & Em curso & Masculino \\
$\mathbf{6}$ & 19 & Não & Em curso & Feminino \\
$\mathbf{9}$ & 19 & Não & Em curso & Masculino \\
$\mathbf{1 2}$ & 23 & Não & Em curso & Masculino \\
$\mathbf{1 4}$ & 23 & Em curso & Feminino \\
\hline
\end{tabular}

Em toda amostra tinham somente 7 pessoas do sexo masculino, e 44,8\% deles estavam entre os 5 de piores desempenhos. Esse resultado demonstra o quanto pessoas do sexo masculino estão pouco envolvidos no assunto da amamentação, primeiro, obviamente, por não amamentarem, mas também por não terem, culturalmente, se dedicado a esses cuidados.

A partir dessa pesquisa vê-se que é necessário algum tipo de instrução para universitários da área da psicologia quanto ao conhecimento sobre amamentação. No entanto, quanto aos conhecimentos dos benefícios sociais e psicológicos da amamentação os participantes demonstraram o mínimo conhecimento. 
O questionário apresentou algumas pequenas falhas, primeiro a quantidade de itens, percebeu-se que os participantes não demonstravam o mesmo entusiasmo para responder as últimas perguntas que o demonstrado no início. Talvez essa questão faça com que os últimos itens não possam ser tão considerados quanto os primeiros.

Os conhecimentos na visão do universitário da área da saúde, em torno do aleitamento materno são de grande importância para o auxílio de mães que poderão ser atendidas na rede de saúde por esses futuramente, podendo evitar assim o desmame precoce. Por isso seria de grande interesse a aplicação de pesquisas com graduandos de Psicologia dos últimos semestres do curso, para se avaliar a evolução e eficácia do conhecimento dos alunos nessa área.

É de grande importância que os profissionais da saúde tenham conhecimento do cotidiano materno e do contexto sociocultural a que pertencem, bem como seus medos, dúvidas, dificuldades e expectativas, para que seja possível desmistificar as crenças consolidadas pelo "senso comum" que influenciam de forma negativa na amamentação.

Percebe-se assim a grande importância que se amplie o debate sobre a atuação do psicólogo na assistência do aleitamento materno, visando potencializar seu desempenho na orientação dessa prática. 


\section{Referências}

Toma, T. S., \& Rea, M. F. (2008). Benefícios da amamentação para a saúde da mulher e da criança: um ensaio sobre as evidências. Cadernos de Saúde Pública, 24, s235-s246.

Ferreira, F. V., Marchionatti, A. M., Oliveira, M. D. M., \& Praetzel, J. R. (2010). Associação entre a duração do aleitamento materno e sua influência sobre o desenvolvimento de hábitos orais deletérios. RSBO Revista Sul-Brasileira de Odontologia, 7(1), 35-40.

Marques, E. S., Cotta, R. M. M., \& Priore, S. E. (2011). Mitos e crenças sobre o aleitamento materno. Ciência \& saúde coletiva, 16, 2461-2468.

de Abreu, F. C. P., Fabbro, M. R. C., \& Wernet, M. (2013). Fatores que intervêm na amamentação exclusiva: revisão integrativa. Revista da Rede de Enfermagem do Nordeste, 14(3), 610-619

SIMÕES, I. A. R. et al (2016). Influência dos mitos e das crenças nas nutrizes quanto amamentação em uma Cidade do Vale do Paraíba. Revista Ciências sem Saúde, Minas Gerais, v. 5, n.3, Jul./Set.

Vaucher ALI, Durman S. (2005). Amamentação: crenças e mitos. Rev Eletrônica de enfermagem ; 7(2):207-214. 